\title{
Thin, fine and with sensitivity: a metamethodology of intuitions
}

Article

Accepted Version

Andow, J. (2016) Thin, fine and with sensitivity: a metamethodology of intuitions. Review of Philosophy and Psychology, 7 (1). pp. 105-125. ISSN 1878-5158 doi: https://doi.org/10.1007/s13164-015-0247-2 Available at https://centaur.reading.ac.uk/40209/

It is advisable to refer to the publisher's version if you intend to cite from the work. See Guidance on citing.

To link to this article DOI: http://dx.doi.org/10.1007/s13164-015-0247-2

Publisher: Springer

All outputs in CentAUR are protected by Intellectual Property Rights law, including copyright law. Copyright and IPR is retained by the creators or other copyright holders. Terms and conditions for use of this material are defined in the End User Agreement.

\section{www.reading.ac.uk/centaur}

\section{CentAUR}

Central Archive at the University of Reading

Reading's research outputs online 


\title{
Thin, Fine and with Sensitivity A metamethodology of intuitions
}

\author{
James Andow
}

the date of receipt and acceptance should be inserted later

\begin{abstract}
Do philosophers use intuitions? Should philosophers use intuitions? Can philosophical methods (where intuitions are concerned) be improved upon? In order to answer these questions we need to have some idea of how we should go about answering them. I defend a way of going about methodology of intuitions: a metamethodology. I claim the following: (i) we should approach methodological questions about intuitions with a thin conception of intuitions in mind; (ii) we should carve intuitions finely; and, (iii) we should carve to a grain to which we are sensitive in our everyday philosophising. The reason is that, unless we do so, we don't get what we want from philosophical methodology. I argue that what we want is information that will aid us in formulating practical advice concerning how to do philosophy responsibly/well/better.
\end{abstract}

\section{Introduction}

The study of intuitions and their role in philosophy has recently occupied the limelight in philosophical methodology, and evaluative methodology is no exception. Evaluative methodology considers aspects of philosophical practice, such as thought experiments or appeals to theoretical virtues, and asks whether they deserve a positive or negative evaluation in some terms or other, e.g., reliability. Some give negative evaluations of intuitions and their use in philosophy, others defend against those negative evaluations. ${ }^{1}$

One can evaluate intuitions in different ways. The terms and the target of the evaluation can vary. By the terms of an evaluative methodology, I mean the terms in which we are to perform the evaluation. It is, of course, very important to specify the terms. Do we want an evaluation in terms of fallibility, coherence,

Philosophy, University of Reading, Reading, RG6 6AA, UK

1 For a helpful introduction, read Pust (2012). Negative positions include those of experimental philosophers, but others as well (e.g., Alexander and Weinberg 2007; Cummins 1998; Haslanger 2006; Hintikka 1999; Kornblith 2007; Machery et al. 2004; Mallon et al. 2009; Nichols, Stich, and Weinberg 2003; Weinberg 2007; Weinberg, Nichols, and Stich 2001; Weinberg et al. Draft of 2006). Intuitions have been defended on a number of bases (e.g., Bengson 2012; Nagel, 2012; Shieber 2012; Sosa 2009). 
beauty, reliability... what? What counts as a merit of philosophical practice? While specifying the terms is important, we also need to know what it is we are to evaluate in those terms, i.e., we also need to know what the target of our evaluation is to be. What aspect of philosophical practice are we to evaluate? Inductive reasoning? Deference to Lewis? Note that saying 'those aspects involving intuitions' doesn't completely settle this issue. Are we to directly target intuitions themselves or their use? Are we to evaluate all intuitions, or, e.g., only the ones philosophers use? ${ }^{2}$ It will not always be possible to know exactly what we will end up targeting from the outset. Nonetheless, we need to know how we will identify our target; it would be good to have what we might call a targeting strategy.

When setting about evaluative methodology, it is important to think about the terms and target of one's evaluation. One reason is clarity. A conclusion like 'intuitions are good/no good' might otherwise be open to many interpretations. It is good practice to state conclusions clearly and unambiguously. However, there is also something more important at stake. Which of the various ways we might evaluate intuitions is the best? The question this paper aims to address is a question about how to pursue evaluative methodology and in that sense at least we might call it a metamethodological one. ${ }^{3}$ The metamethodological question is:

(a) How should we go about evaluating intuition-using philosophy?

The answer to questions of this form, i.e., questions like 'How should we go about doing $\mathrm{x}$ ?', is often, 'It depends'. In particular, the answer often seems to depend on what motivates our interest in doing $\mathrm{x}$ in the first place. For example, how one should practice one's scales depends on whether one aims to be a jazz pianist or a baroque harpsichord player. For another, suppose I run into your study and ask the best way to hide a body. You should try to find out why I want to know. 'Throw a coat over it' will count as a bad answer if I am looking to avoid arrest for murder, but a perfectly satisfactory answer if I simply don't like the look of the thing and want it out of sight.

I am inclined to think that our metamethodological question is no different. There are various more general aims one might have which motivate an interest in evaluating philosophical methods and which of these one has affects how one should evaluate. If you want an evaluation of philosophical methods in order to help weed out overly expensive ways of doing philosophy, then your evaluation better be in terms of economic efficiency - whatever that would mean. ${ }^{4}$

2 The thought that we should concentrate on the intuitions philosophers use is the idea behind the 'expertise defence' advanced and defended by a number of philosophers in response to challenges by experimental philosophers (Andow forthcoming; Hales 2006; Horvath 2010; Kauppinen 2007; Ludwig 2007; Singer 1982, 2005; Sosa 2010; Williamson 2005; Williamson 2007, 2011).

3 I don't intend to defend a principled positive account of the distinction between methodology and metamethodology, neither do I need to for my purposes. The point is simply to take a step back from particular projects in evaluative methodology and consider how such projects are best approached. The label 'metamethodology' provides a useful way to captures this for me. Use of this label doesn't commit me to saying generally that 'how should we evaluate x?' is a meta[something] question.

4 One might think that it is not what motivates you but what should motivate you which matters. For example, regardless of whether you want cheaper philosophy, perhaps you really ought to want more consistent philosophy. I am not sure about this. However, if that is right, then what I say in the rest of the paper still follows. This is due to the minimal/non-substantive 
The aim of this paper then is to reflect on what we might call the motivational question and ask what this can tell us about how the evaluation of intuition-using methods in philosophy should be conducted. The motivational question is the following:

(b) What do we want from an evaluation of intuition-using philosophy?

This paper advances and explores one answer to the motivational question. The answer it advances is broadly that we want our evaluative methodology to help us do better philosophy. I argue that reflecting on this answer allows us to settle three particular issues concerning how evaluative methodologists should think about intuitions when going about their evaluation. These are the following (for now, they involve some unfamiliar terms): (i) whether we should have a thick or a thin conception of intuitions when doing evaluative methodology; (ii) whether we should evaluate intuitions monolithically; and (iii) what the best way to carve a monolith is. My answers will be roughly that we should approach the evaluation of intuitions with a thin conception of intuition, prepared to carve up intuitions rather than treat them monolithically and that we should be prepared to carve to any distinction so long as we can make that distinction in the course of our everyday philosophising.

It is never too early to see off an obvious objection. Why think that metamethodological reflection is necessary in order to work out how methodologists should think about intuitions? We can agree that perhaps the terms of one evaluation depend on what one wants from an evaluation (if you want cheaper philosophy, evaluate in some economic terms). What, however, can be wrong with the idea that our first step in evaluating intuition-use in philosophy simply has be to identify the target - to identify what intuitions are, e.g., to determine to which mental state(s) philosophers refer to when they use the word 'intuition'? The answer is that there is nothing intrinsically wrong with such an approach. It is just that it seems to be rather difficult. Conflicting ways of thinking about intuitions and their use abound in philosophy. Genuine intuitions are variously hailed to involve peculiar seemings, be a type of belief, be non-beliefs, be immediate judgements about cases, be reflective judgements, be largely innate, be wholely acquired, and so on. Evaluative methodology has a habit of stagnating - to get bogged-down in debates about whether one or other party involved is characterising intuitions correctly (for some examples of the types of debate I have in mind see $\S 6$, p.13). Time gets spent in debates about whether experimental philosophers tap intuitions and what sorts of things intuitions are, for instance - debates which appear to be making at most slow progress - rather than in activities which provide lots of concrete advice on how to do philosophy better.

My project in this paper - taking a step back to do some metamethodological reflection - is motivated by a desire for a different approach. I want to be able to approach evaluative methodology of intuitions without having to become embroiled in tricky (and at times, one suspects, intractable) debates about what intuitions really are. ${ }^{5}$ This paper demonstrates that such an approach is possi-

nature of the motivation I consider in the next section. It doesn't really seem plausible to say that one's interest in evaluative methodology ought not to be motivated by wanting philosophy to be done well (where this is neutral as to precise axiology).

5 Not that tricky debates should always be avoided in philosophy. The rationale is that when debate A is very tricky (and is suspected to be intractable), settling debate A is unnecessary 
ble and makes concrete recommendations about how evaluative methodologists should think about intuitions. The take-home message is that we don't have to have a fully developed account of intuitions - one which will hold its own outside of evaluative methodology, e.g., when taxonomising mental kinds - in order to productively evaluate philosophical methods where intuitions are concerned. One can put other debates about how to characterise intuitions aside when doing evaluative methodology and resolve to simply characterise intuitions in the way which will set up one's evaluative project to give useful information about how to do philosophy better. This doesn't commit one to using that characterisation when doing philosophy of mind or when theorising about our basic sources of warrant. Neither does this commit one to thinking that the relevant characterisation is the all things considered best account of what intuitions really are. The issue of how to think about intuition when doing evaluative methodology can be treated as completely ancillary to the question of what intuitions are really; philosophers who have divergent and irreconcilable views about what intuitions really are can nonetheless agree with me about how we should think about intuitions when doing evaluative methodology.

\section{What do we want from an evaluation of intuition-using philosophy?}

Let's grant that philosophers do use intuitions (given some reading of 'intuitions'). ${ }^{6}$ Why would we evaluate that use? Why would we value the evaluation of extant philosophical practice? Why would we be interested in finding out which methods are good ones and which ones bad (in whichever terms)? I offer the following as the most plausible motivation: we want to do the best we can as philosophers; we want to be responsible philosophers; and, if we worry about whether our methods are any good, it is because we want to know whether we should be giving them up, using other ones, or improving our practice. ${ }^{7}$

I appreciate that this is a fairly minimal/non-substantive suggestion. This might seem problematic. The thought might be, perhaps, that it isn't clear what the motivation really amounts to. It is of course true that 'wanting to do philosophy better' really doesn't conflict with any other ideas one might have about what constitutes better philosophy or other motivations one might have for getting involved in evaluative methodology. For example, you might get involved because you want methods which give you lots of true beliefs, but, if you do, you presumably think that philosophy which arrives at true beliefs is better philosophy than that which doesn't, all else being equal. So the motivation 'wanting to do philoso-

\footnotetext{
for making progress in debate $\mathrm{B}$, and debate $\mathrm{B}$ is really what you want to settle, in that case there is good reason for you to avoid debate $\mathrm{A}$.

6 The assumption that intuition-use is extant practice is fairly innocuous, as I do not suppose any particular account of what intuitions are or how philosophers use them. Philosophers definitely use the word 'intuition' in their philosophising. Indeed in some analytic publications the proportion of papers, in the period 2000-2009, indulging in intuition-talk is over $85 \%$ (Andow 2015). It is interesting to note that although the evaluation of extant practice is more interesting than that of how philosophy is done in some science fiction version of the profession is less interesting, the evaluation of non-extant practices, e.g., historical methods may be of some interest.

7 I write in the first person plural. If your interest in having better methods is purely selfish, much the same lessons follow-just translate into the singular.
} 
phy better' doesn't conflict with the motivation 'wanting true beliefs'. But neither would it conflict with 'wanting false beliefs' And it is easy to see that the same goes for other motivations 'wanting philosophy to cause lots of deaths', 'wanting beautiful philosophy', and 'wanting philosophy done by shiny people'.

My suggestion really is that minimal/non-substantive. But, this is okay. There is no cause for worry. I am not aiming to give any account of what makes a philosophical method good or better than another. I understand that saying ' $I$ want better philosophy' won't help you sort between philosophical methods unless you have an accompanying axiology. But that's okay, because I am not trying to sort between philosophical methods. I am trying to sort between ways of doing evaluative methodology. ${ }^{8}$ And, as we will see, the mere idea that the reason we want to do evaluative methodology has something to do with wanting the best methods (regardless of what one thinks the best methods actually are) does help us do just that - does help us sort between ways of doing evaluative methodology.

The main insight this suggestion provides is the following: if you are motivated as I suggest, then you should evaluate methods in such a way that its deliverances can help us be more responsible philosophers (if this is possible) - whatever you happen to think makes a responsible philosopher. Accordingly, we want evaluations that we can use to guide our practice. It should be fairly clear that it would be a fantastic shame if, when we go away and evaluate our methods or some aspect of our methods negatively, we were not able to use any information resulting from that process of evaluation to, for instance, take evasive action- even if that evaluation is accurate. ${ }^{9}$ If a set of intuitions is negatively evaluated, we ideally want to be able to form ameliorative strategies using that information. A strategy of evaluation which doesn't provide any information which is useful in this way just doesn't do what it was we wanted evaluative methodology to do for us. Moreover, given a choice between two strategies of evaluation, the one which provides the more useful information is the better strategy.

Consider the following example. Suppose that $5 \%$ of our intuitions result from the activity of an evil demon who tries to deceive us, the remaining $95 \%$ of intuitions are highly reliable, but that we don't have the resources to determine which particular intuitions result from evil demon activity. Suppose now that we do some evaluative methodology and find out the following piece of information: intuitions which result from evil demon activity oughtn't to be trusted. While our evaluative methodology may produce results which are epistemologically sound - it may be true that we ought not to trust these intuitions - this information would not enable us to take any appropriate evasive action (one could avoid intuition-use entirely, but this would mean abandoning a lot of good sources of evidence). Of course, the information we receive about the demon isn't completely useless. Some action seems appropriate on receiving this information, e.g., reducing the extent to which we trust intuitions by some relevant margin. However, compared with an evaluation which allows us to identify the problematic intuitions, the information about the demon is a poor substitute.

\footnotetext{
8 We could quibble about how to divide up the territory here. Methods of metaphilosophy are philosophical methods, might be the thought. Be that as it may, I take it the distinction I intend to track here is clear.

9 Of course, if you have some other motivation, then this might be no problem at all.
} 
In the following, I argue this has a number of implications for how we ought to conduct an evaluation of intuition-use in philosophy. In particular, I argue this motivation helps us settle three issues. Let's consider the first.

\section{Thick or Thin}

When one sets out to evaluate intuitions, it is important to know what you mean by 'intuitions'. Philosophers have famously characterised intuitions in a number of different ways and it is important to know which of these (or which other) one is using. One important distinction here is that between thick and thin conceptions of intuition (this distinction is introduced by Weinberg and Alexander forthcoming). The question is whether we should approach the evaluation of intuitions with a thick or a thin conception of intuitions.

Let's be clear about the distinction. Thin conceptions identify intuitions merely as 'instances of some fairly generic and epistemologically uncontroversial category of mental states or episodes' (forthcoming, §1). Weinberg and Alexander identify Williamson as a proponent of a thin conception of intuitions. Williamson (2007) 'encourages a ... view according to which intuitions are (at most) just judgements or inclinations to judge' (forthcoming, §2). (Weinberg and Alexander also cite Lewis 1983, van Inwagen 1997, Cappelen 2012, and Buckwalter \& Stich 2010, as being proponents of thin conceptions.) On the other hand, thick conceptions are less inclusive and impose some restrictions. Various restrictions which might be imposed include: having a particular (perhaps special) type of content (e.g., BonJour 1998; Sosa 1998); having some distinctive phenomenology (e.g., Bealer 1998; Bengson 2012); or having a particular etiology or deriving from a conceptual competence (e.g., Ludwig 2007; Sosa 1998; Bealer 1998; Kauppinen 2007 - these are Weinberg and Alexander's examples).

What is at stake in approaching the evaluation of intuitions with a relatively thin/thick conception of intuitions? Helpfully, Weinberg and Alexander (forthcoming) consider a number of relevant consequences of conceiving of intuitions thinly and thickly respectively. Their discussion occurs in the context of a rather different question, however, so we'll permit ourselves a quick digression to say something about their project, before noting how the considerations they make are relevant to our metamethodological question.

Weinberg and Alexander's discussion relates to the recent empirical challenge to the reliability of intuitions. The supposed evidence that intuitions are unreliable comes mainly from survey-based studies conducted by experimental philosophers. Weinberg and Alexander note an interesting dialectical tension in relation to this empirical challenge:

It seems that philosophers face a dilemma on a sliding scale: the thinner their conception of philosophical intuition, the more clearly they are challenged by recent work in experimental philosophy; the thicker their conception of philosophical intuition, the more likely they are to incur different kinds of methodological problems and the harder it will be to tell when anyone is doing philosophy correctly. (p.20, prepublication copy) 
The basic thought is that it is fairly safe to infer facts about participant's judgements, inclinations to judge, beliefs or inclinations to believe, etc., from the results of surveys. Consequently, if intuitions are conceived thinly then it is easy to use surveys to find out about participant's intuitions (pace worries such as those of Cummins 2009). But, thick conceptions make the inference rather more tenuous. Once one starts to add etiological or phenomenological restrictions, for instance, it is less clear that surveys reveal much about intuitions; for, we know little about participants' phenomenology or where their judgements come from. A result of this is that intuitions thickly conceived are not as directly open to the empirical threat.

Nonetheless, Weinberg and Alexander note a number of reasons to think that those with a thick conception of intuitions still do not have an effective way to resist the empirical challenge. I'll look at two main reasons here. ${ }^{10}$

(1) Thick characterisations don't always paint a very rosy picture of traditional philosophical practice. On certain thick conceptions - particularly etiological approaches - it is very unclear how we would be able to reliably tell the difference between intuitions and non-intuitions from the armchair. The origins of our intuitions are typically fairly opaque to us, at least from the armchair. In fact, intuitions are often characterised as not resulting from conscious reasoning processes (e.g., Gopnik \& Schwitzgebel 1998; Mercier \& Sperber 2008; Nahmias et al. 2006). If such a conception were to be insisted upon, one might be able to successfully defend the practice of relying on intuitions, but only at the expense of granting that it is very difficult to work out when philosophers are engaging in that practice.

(2) In order to resist the challenge it seems that you must have some reason to think intuitions as you thickly characterise them do not exhibit the same problematic effects that show up in the empirical evidence. If one thermometer of a batch is faulty, pointing out that the rest of the batch may not be faulty is not good enough unless one can provide reason to think the faultiness is isolated. In the case of thermometers, such reasons may be forthcoming. Perhaps the glass has shattered in a way which doesn't indicate that the crate was dropped. However, some ways of characterising intuitions thickly, seem to have quite the opposite feature. There is positive reason to expect intuitions, given typical phenomenological or etiological restrictions, won't be immune from problematic effects. First, Weinberg and Alexander discuss Bengson's (2012) proposal that genuine intuitions strike us a certain way which they identify with the tradition of talk of intellectual seemings. They present evidence that the types of psychological mechanism whose deliverances are typically associated with seemings are also typically susceptible to epistemically worrying effects, e.g., framing effects. Second, they discuss conceptual competence views, and note that how much cause for optimism those with such a view have depends on what theory of concepts is assumed. The problem is, firstly, that the prominent empirically plausible accounts of concepts,

\footnotetext{
10 Weinberg and Alexander also note the further worry that insofar as any defence is supposed be a defence of traditional or current philosophical practice, those using thicker conceptions, e.g., intuitions*, run the danger of missing their target, as philosophers show few signs of using intuitions*. For, consider some of the various 'thickeners': having a deep sense of necessity, or being the result of conceptual competence. It might be thought rather implausible that currently or traditionally philosophers show a great deal of sensitivity to whether a judgement is accompanied by such a phenomenology or has resulted of a true conceptual competence.
} 
"... attribute structures to the mind that are themselves contextually sensitive and widely variable across both individuals and populations - for example, theories according to which our concepts contain representations of exemplars ... or theories according to which sensitivity to contextual factors is practically a defining characteristic" (Weinberg and Alexander, forthcoming, pp. 16-17).

And, secondly, that to defend intuition-use while relying upon an alternative account of concepts, e.g., one which imposes "context-free sets of necessary and sufficient conditions on category membership" (p.17), involves taking on empirical commitments which have little support from current findings.

In sum: Weinberg and Alexander present some problems one might face if one characterises intuitions in a thick way. These are problems one faces if one is interested in defending intuitions against the empirical challenge.

Remember that my project is a little different. I want to know whether approaching evaluative methodology with a thick or thin conception of intuitions makes a difference to how useful the results of the evaluation will be to us in trying to do philosophy better. ${ }^{11}$ Nonetheless, the considerations Weinberg and Alexander make are relevant.

We want our evaluation to give verdicts about targets our colleagues can discern while philosophising. As Weinberg and Alexander note, thick conceptions run the danger of making the target rather obscure from the armchair. Not all thick conceptions face this problem. Phenomenology may be accessible from the armchair, for instance. We should note, however, that such a characterisation could face other difficulties, depending on the terms in which we want to conduct our evaluation. Suppose the terms were to be such that the only appropriate way to evaluate in those terms involved the empirical examination of intuitions. As Weinberg and Alexander note, it is less clear that empirical work on 'intuitions' bears on intuitions conceived in such a manner. Depending on the particular phenomenological conditions imposed, it could be rather difficult to ensure that one was evaluating one's intended target; if you set out to evaluate intuitions (characterised thickly with certain phenomenological restriction), that might not be an achievable task. This is only a potential problem. It should not prevent us from considering such characterisations. However, we should bear in mind that it is not just being able to tell intuition from non-intuition from the armchair which counts, but also being able to do so when performing the evaluation, for it may be that evaluations of intuitions are not best performed from the armchair. The potential problem is not faced only by phenomenologically-specified thick accounts. Accounts which demand a particular etiology, e.g., deriving from a competence, threaten to make it difficult to distinguish intuitions from non-intuitions while evaluating them as well. Accounts that require a given quantity or quality of reflection also threaten to make the empirical evaluation of intuitions very difficult (the latter might require experiments which take decades!).

\footnotetext{
11 Of course, there will be further decisions to be made. If we go for a thick conception, we will need to ask which. In fact, it is somewhat artificial to present the evaluative methodologist as facing a choice between thick and thin at such a general level. However, it is illuminating to think about what is at stake in approaching evaluative methodology with either kind of conception in mind.
} 
In sum then, conceiving of intuitions thickly could make it difficult to assess claims about the merits of intuitions. However, Weinberg and Alexander's concerns about thin conceptions are also apt; conceiving of intuitions in a thin way may leave one (a) without resources to respond or avoid the restrictionist's challenges and (b) running the risk of 'discounting important differences between various kinds (e.g., memorial, introspective, perceptual, inferential, testimonial, and even more narrowly construed intuitional kinds) of philosophical evidence - differences that figure significantly into questions of reliability, defeasibility, and conflict resolution' (Weinberg and Alexander: 4). I turn now to consider a distinction made clear in a recent paper by Jennifer Nado. What she has to say makes it clear that adopting a thin conception of intuitions doesn't have to mean we face these costs, i.e., (a) and (b).

\section{Monoliths}

The question to be addressed is whether we should evaluate intuitions monolithically. The answer will loosely be that we shouldn't. The idea of monoliths is introduced by Nado (2012) who argues against the evaluation of monoliths.

Nado notes that the debate about whether intuitions are any good is often framed in a particular way, and she proposes an alternative. According to this typical way of framing the debate, the target of evaluation is assumed to be 'a monolith': 12

Though the criticisms and defenses of intuition which have arisen over the past fifteen or so years are quite varied, there is a general - though admittedly not universal - tendency to write as though the intuitive judgments invoked by philosophers stand or fall together, and that their doing so will be a consequence of the reliability or lack thereof of some unified mental capacity called 'intuition'. (Nado 2012: 3)

Suppose we accept that we should evaluate intuitions in terms of reliability. What is the advantage to a non-monolithic approach? Nado motivates her preferred targeting strategy by noting that it is very plausible there is some form of 'deep diversity' among the psychological mechanisms underlying the various states philosophers have called 'intuitions' (Nado 2012: 23). The point is that our psychology seems to involve a lot of very domain-specific processing and it seems plausible that the processes involved in certain intuitions will be completely unrelated from those involved in certain other intuitions. ${ }^{13}$ Some of these processes might be reliable, some might not.

Nado argues that this has consequences for advocates of the monolithic approach,

\footnotetext{
12 Nado doesn't claim all philosophers think intuition is to be evaluated monolithically but rather that this seems to be the default way of framing the debate. I am inclined to agree the debate does get framed this way, but won't defend this claim. Another similar way the debate gets framed is by pitting Restrictionist against Cathedrist (e.g., Weinberg et al. 2010), i.e., by characterising those in the debate as pro- or anti-intuition simpliciter.

13 I don't review the evidence Nado presents, nor the resultant picture of the mind. Suppose it is broadly right that psychology is this way.
} 
... if there are in fact diverse psychological processes underlying different subsets of 'intuitive' judgments, then philosophers in the business of arguing for or against intuition need to provide arguments as to why reliability assessment should not target these processes individually (p.26).

Indeed, if we add our motivation of wanting to be better philosophers to these considerations, the need for advocates of the monolithic approach to defend their approach is even more pressing; our motivation spurs a move away from monolithic targets and towards more finely-carved targets. The reason is that doing so will give you a richer source of good advice. The advice you get from a monolithic evaluation is simply a resolute boo or hooray for the intuitive. More subtle advice, however, allows you to avoid certain intuitions, and accept others - to separate baby from bathwater. ${ }^{14}$

Two important questions now arise. How finely should the evaluative methodologist carve the monolith? And, to what grain? Nado is clear what the method of carving should be: intuitions are to be carved according to the grain of the psychology underpinning them. ${ }^{15}$ Given this, Nado thinks the carving will end up being on the fine end of the scale. As, she thinks that psychological processing is likely to pretty diverse. In the next section, I will challenge Nado's answers to these questions and answer them for myself.

To complete this section, let me make clear another advantage of a nonmonolithic evaluative strategy. In the previous section, we noted a number of potential disadvantages of adopting a thin rather than thick conception of intuitions. Note that these disadvantages only face methodologists who are committed to a non-discriminating monolithic approach to the evaluation of intuitions; this is true regardless of the terms in which one evaluates - reliability, beauty, what-haveyou. The worries were that on adopting a thin conception we might lose out on important distinctions between types of intuitions nor the opportunity to respond to the restrictionist by questioning their failure to discriminate. But we don't; one can have a thin conception of intuition, yet be prepared to discriminate. ${ }^{16} \mathrm{I}$ could

\footnotetext{
14 I take it few people really think all intuitions deserve a negative evaluation, certainly given a thin conception of intuitions. Nonetheless, if all intuitions deserve a negative evaluation, the approach I recommend doesn't prevent us from finding that out. One might, for example, find that there is an unreliable mechanism at the heart of all our intuition generating processes. The rejection of the monolithic approach is a rejection of being committed to only evaluating intuitions en bloc.

15 I should note that Nado says some things which suggest she thinks the carving might result in categories "like 'moral intuition', 'epistemological intuition', and so forth". However, even in this case, she qualifies it: "This is indeed one possible way to re-carve the intuitive terrain, but I wish to emphasize that it is not the only possible approach. In fact, the evidence reviewed above suggests that the actual situation may be far more complicated; even within domains like moral or logical cognition, substantially different types of processing may be involved. If this is right, the epistemological features of philosophical methodology may be even more complex." (p.22-23)

16 One genuine loss involved in adopting a thin conception is that of a rhetorical device. Thin conceptions of intuitions make claims like 'the evidence you present doesn't show that intuitions are unreliable' somewhat implausible, and being able to say such things is an asset to the restrictionist's opponent. However, while natty turns of phrase are nice, they don't constitute strong reasons to adopt a view. One still make the same points if you conceive of intuitions thinly, e.g., 'the evidence you present shows that some intuitions are unreliable, but doesn't show that [a particular subset of intuitions which I use in philosophising] are unreliable'.
} 
treat my cat as a type of intuition. But this wouldn't commit me to giving a single evaluation for all intuitions (including my cat).

\section{Carving}

Evaluating monoliths, or at least, being committed to a monolithic evaluation, seems like a bad idea. However, it seems that there might be something to be said against Nado's method of carving. Weinberg (2007) proposes an alternative: carving according to subject matter. While Weinberg is generally down on intuitions, he admits intuitions about some particular subjects might make the cut; to whit, mathematical and logical intuitions, intuitions which are partly constitutive of folk psychology, and intuitions about epistemic norms. Our appeals to intuition in these domains are okay, he thinks, because we have, with respect to these subdomains, the resources to help detect and avoid their error within our practices.

So Weinberg's approach differs in a number of respects to Nado's. The targeting differs: what we should be evaluating is not intuitions themselves (or the capacities which produce them), but philosophers' practice of appealing to intuitions. But the suggested terms also seem to differ. Certainly he thinks that brute level of reliability of intuitions in a subdomain doesn't itself tell you how much you should trust them. The idea is that use of a source which is, say, $60 \%$ reliable might be okay, if our practices are such that we are capable of detecting and avoiding its mistakes, but not okay otherwise. So, Weinberg opts rather to evaluate in terms of some feature of our practice (which he calls 'hopefulness') - the ability to detect and avoid error. ${ }^{17}$ Given that Weinberg thinks we should be evaluating philosophers' practice of appealing to intuitions in terms of hopefulness/hopelessness, it is clear why he advocates carving by subdiscipline. Nonetheless, this method of carving is worth considering, even if we don't agree that the target of the evaluation should be practices or that the terms should hopefulness/hopelessness.

Our guiding thought has been that our method of evaluating intuitions ought to be such that its deliverances can help us be more responsible philosophers-better philosophers. I argued that should mean that we want evaluations we can use to guide our practice. Consequently, what matters is that the discriminations we make in our evaluating of intuitions (in our carving) are by and large distinctions to which we are sensitive in the process of our philosophising. Suppose, for example, that experimental philosophers find that subjects' responses to a certain thought experiment $\mathrm{X}$ show variation which cannot be explained away. The reason this is potentially helpful information is that we are sensitive to the distinction between $\mathrm{X}$ and other thought experiments. I don't mean that we are ordinarily sensitive to the fact that intuitions about $\mathrm{X}$ have this variability. I mean simply that we can tell the difference between thought experiments. We can resolve not to use

\footnotetext{
17 In fact, it isn't clear the distinction between hopeful and hopeless practices doesn't amount to the distinction between having reliable and unreliable practices. However, I won't argue for this here. Others have noted close connections between the reliability of source and the hopefulness of our relying on that source (see Brown 2011; Horvath 2010), although, not the apparent equivalence of considerations of hope and reliability (at the level of our use of a source).
} 
intuitions about $\mathrm{X}$ because we can tell which thought experiments are instances of $\mathrm{X}$.

Nado's approach doesn't fare well in this light. Since we are typically not sensitive to the precise etiology of our intuitions, information about the reliability or otherwise of the various psychological mechanisms which produce intuitions will not be of much help in, e.g., assigning evidential weights to intuitions. ${ }^{18}$

This is not to say that such information can never be helpful. Insofar as we are sensitive in our philosophising to the grain of the psychology of intuitions, our evaluative strategy should feel free to make those distinctions too. ${ }^{19}$ However, I see no reason to restrict our discriminating to psychological grounds. But, neither is there any reason to stop at the distinctions we can make between various subdisciplines. We are aware of many things about our intuitions: the speed of intuiting, the amount of deliberation we take in coming to have an intuition, the light levels at the time of the intuiting, the general subject matter of the intuition (e.g., epistemology), the specific subject matter (e.g., a fake barn case), our approximate level of expertise in that subject matter, the wording we use, etc. These distinctions could be epistemically relevant - in the sense that they could help sort wheat from chaff-even if they don't carve up our psychological mechanisms in any psychologically important or principled way (and despite not necessarily being distinctions which are obviously of intrinsic epistemic relevance).

So, this is where the guiding thought has lead us. If we want an evaluative methodology whose results will help us be better philosophers and do better philosophy, it seems we should start with a thin conception of intuitions, but be prepared to carve, avoiding a monolithic evaluation of intuitions, and to take advantage of any distinctions so long as we are capable of tracking those distinctions in the process of our philosophising. Doing this will ensure that the information we get can be of use in improving our practice. ${ }^{20}$ For example, we can track whether or not we are thinking about cases involving features which are personally very emotionally involving. Consequently, information about the comparative stability of judgements about such cases is information which I could use in deciding how much credence to place in my various intuitions.

Note that my claims here in no way entail that evaluative methodology should be an affair confined to the armchair. Indeed that is a proposal to which I am not in the least friendly. Evaluative methodologists should carve intuitions according to distinctions which can be tracked from the armchair, but they likely shouldn't do it from the armchair. We can track the distinction between intuitions about

\footnotetext{
18 An anonymous referee thought this might be irrelevant as it isn't within the remit of philosophy to be sensitive to etiology in this way. (1) I don't agree, and (2) my point here isn't to say that philosophers aren't doing their job, it is simply that we can't tell which intuitions come from which mechanisms (by and large) and that, accordingly, knowing, for instance, that intuitions from mechanisms XYZ are unreliable, won't be of any help, as we can't identify which intuitions come from those mechanisms.

19 Moreover, I don't mean to be dismissive about the extent to which we can be sensitive to etiology. For instance, if it turned out that intuitions from process A made my ears wiggle and intuitions from other processes didn't, then I could track this distinction from the armchair. I don't intend to restrict the methodologist to investigating distinctions between intuitions with etiologies which, for example, present themselves in the content of the intuitions, or are otherwise directly introspectable.

20 Remember that this conclusion concerns only how one should think about intuitions when doing evaluative methodology. It is not advocated, on this basis, as the correct account as to what intuitions actaully are.
} 
logic and intuitions about epistemology from the armchair, but we likely can't gather the sort of data we would need to evaluate those categories of intuition wihtout some empirical enquiry.

One interesting possibility which it is worth discussing briefly is the idea of intuitional prosthetic aids (IPAs). ${ }^{21}$ An IPA is a device which one can use in the process of philosophising that provides you with information about your intuitions which would not be otherwise available to you. Suppose that our intuitions are less reliable when our blood sugar falls below a certain level. Information about our precise blood sugar level is not typically available to us from the armchair. Consequently, the considerations so far in this paper would suggest that the evaluative methodologists ought not to concern themselves with the distinction between intuitions when one's blood sugar is at certain levels. However, if there was the possibility of an IPA, a pager that sat in one's top pocket and monitored one's blood sugar level, then perhaps evaluative methodologists would not be wasting their time with such distinctions. Just because a distinction is typically not accessible from the armchair, doesn't mean that it might not be with the aid of a cheap and easy prosthetic. I think this is right and so perhaps the view as stated above needs to be relaxed slightly: the distinctions with which the evaluative methodologist should bother are those to which philosophers are typically sensitive and perhaps those to which they could be sensitive with judicious use of a cheap and easy prosthetic. An IPA could be something simple as a short questionnaire to judge mood - something which philosophers could use easily, but don't. ${ }^{22}$

\section{So what?}

The main objection I foresee is that it is unclear who would contest my main claims. One reason for this might be that, to some degree, I am talking past the literature which I cite. The various philosophers I cite above are typically not involved in a debate about the best way to think about intuitions for future inquiry about intuitional methods. This is due to the fact that extant debates about how to think about intuitions do not have this focus. A second reason for this might be that it is not clear what practical implications what I say has for would-be evaluative methodologists. Let me briefly address both concerns.

While it is true that most debates about how to think about intuitions have not been focused on how to think about them for future inquiry about intuitional methods, I think this is a pity. That is not to say I think all debate about how to characterise intuitions should have this focus. There are many reasons one might

\footnotetext{
21 Thanks to Jennifer Nagel for this suggestion.

22 An anonymous referee asks what empirical data I would allow an IPA to detect. The answer is, in principle, any! The only restrictions will be practical ones. This is the reason why I specified that IPAs must be cheap and easy. There is no point in evaluative methodologists busying themselves with distinctions which philosophers could track while philosophising but only with the help of an fMRI scanner. We can't be expected to do all our philosophising from within an fMRI machine. The information and advice provided should be able to be of practical help to philosophers which necessitates that the devices required are not too expensive or cumbersome to use.
} 
be interested in thinking about how to characterise intuition(s). The problem arises with a failure to recognise that the questions of how one should characterise intuitions for future work in evaluative methodology and how to characterise intuition(s) given other purposes are distinct. I think such a failure has been a distraction in the debate (and, I suspect, has hindered the ability of evaluative methodology to help us do philosophy better) ${ }^{23}$ Broadly, the way of thinking which I think leads to problems is to think that when methodologists perform an evaluation, which has to do with philosophers' use of intuitions, it is of the utmost importance that they characterise intuition(s) in the 'correct' way. (An analogy may be helpful. Here's one: Suppose you are trying to do something to tackle the gender imbalance in philosophy. One could start by establishing a completely satisfactory theory of gender in terms of ontology, psychology, etcetera. However, that seems like a mistake. What you want is strategies that work. and such strategies need not involve a completely satisfactory account of gender.)

The failure to recognise that the two types of question are distinct is apparent in a number of types of move in the methodological literature.

(1) It is fairly common to think that methodologists have made a big mistake if the way that they characterise intuitions gets the psychology or metaphysics of intuition(s) wrong-perhaps that their results are methodologically irrelevant as a consequence. In other words, it is common to assume that the answer to the question of how one should characterise intuitions for future work in evaluative methodology must be same as the answer to the question of, for example, how one should characterise intuitions if you want accurate psychological theory of intuitions. The idea is apparent in the strong criticism of evaluative projects, in particular empirical evaluative projects, on the basis that the target of their evaluation wasn't really intuitions - criticism on the basis of a substantive account of what intuitions are. Weinberg and Alexander (forthcoming) identify a number of culprits in this respect: Bealer (1998) defends intuition-use against negative evaluations made on empirical bases saying "although [the empirical findings of cognitive psychologists] bear on "intuition" in an indiscriminate use of the term, they evidently tell us little about the notion of intuition ... which is relevant to the justificatory practices ... philosophy"; and Ludwig (2007) builds a response on the worry that "responses to surveys about scenarios used in thought experiments are not ipso facto intuitions". ${ }^{24}$

But, while such criticisms could be very important vis-à-vis any inferences researchers want to make about the properties of intuition (given a characterisation which properly captures, e.g., the psychological phenomenon), they are much less important when it comes to what/whether we can learn about how to do philosophy better. Having a loose/thin characterisation which doesn't carefully distinguish mental kinds, or marry easily with a thesis on the ontology of evidence, just isn't a good criticism of an evaluative project qua project whose purpose is to

\footnotetext{
23 My point is similar in kind to Nado's. Nado (2012) notes that the methodological literature has been distracted by the idea of a monolithic evaluation of intuitions. I note a similar distraction.

24 Weinberg \& Alexander themselves remain fairly quiet concerning how one should think about intuitions independently of the dialectical implications of adopting certain conceptions in the debate between cathedrist and restrictionist. Weinberg and Alexander (forthcoming) mention also include Cullen (2010), Bengson (forthcoming), and Kauppinen (2007) among the culprits.
} 
give us information which can help us in doing philosophy better. And, as I have suggested, what we really care about in evaluative methodology is the latter.

Remember that I am not saying that approaching evaluative methodology of intuitions by first establishing what exactly philosophers are talking about when they talk about 'intuitions' is somehow inherently problematic. It is simply a contingent fact that it seems very difficult to establish any such account. There is a very real risk of getting bogged-down in debates which are really besides the point: debates about, for example, whether intuitions are being mischaracterised by certain parties in the debate. My point is simply that there is an alternative approach which can avoid getting bogged-down in this way. One can set aside the issue of what intuitions really are and ask how we should think about intuitions when doing evaluative methodology and it turns out that we can quickly get clear answers about the latter question.

(2) It is fairly common think that it is appropriate for a methodological evaluation to target intuitions monolithically, simply in virtue of the fact that intuitions are a distinct sui generis mental/psychological kind or a basic evidential source. Nado identifies Bealer (1998) and Pust (2000) as making such assumptions. ${ }^{25}$ In other words, it is assumed that once you have an answer to the question Whats the best psychological/epistemic model of intuition? you have an answer to the question How should one characterise intuitions for future evaluative methodology? But that isn't necessarily right. As Nado recognises, non-monolithic reliability assessments of intuitions would provide more accurate assessments of the epistemic merits of particular intuitions (than would assessments targeting the single category 'intuitions'). However, even Nado fails to quite appreciate that the real benefit to methodologists to treating intuitions (somewhat) heterogeneously is that the results of their evaluations will be much more useful in working out how to improve our philosophical practice. But, the matter of how evaluative methodologists target their evaluation doesn't seem to be best decided by working out what mental kinds there are, what our basic sources of evidence are, or even what psychological mechanisms underlie our intuitions. Such concerns aren't completely irrelevant, but they oughtn't to be in the driving seat. (They aren't completely irrelevant because such information might concern distinctions which can be tracked in the process of philosophising. However, it is this latter concern which should be in the driving seat).

(3) Methodologists have been recently criticised on the basis that philosophers don't really use intuitions. The potential impact of this criticism for evaluative methodology should be clear: there is no methodological benefit to evaluating things which philosophers don't use. ${ }^{26}$ There is something wrong with this line of thought, however. This sort of criticism must rely on some fairly substantive account of what it would be to rely upon an intuition. If the claim is that philosophers never use judgements about cases, then it is obviously false, for instance (indeed, that simply isn't what the folks leveling such criticism have in mind). So, suppose that when doing some evaluative methodology we characterise intuitions

\footnotetext{
25 Other parties Nado identifies as being guilty of treating intuitions monolithically (or talking as if they are doing so), don't obviously have such principle in the background, e.g., Sosa (2007), Cummins (1998), Weatherson (2003) and a number of experimental philosophers.

26 I take this to be the central point of Cappelen's (2012) criticism of experimental philosophy, although there are a lot of subtleties in Cappelen's work too, which I don't have time to get in to.
} 
as simply as being judgements (no one would deny we use judgements in philosophy). Even an evaluative project that targeted the various judgements we use in philosophising would have a lot to contribute - identifying subclasses which we want to avoid, and so on.

I don't intend what I say here as a major criticism of the authors I have cited. As I say, none of them are focused on the question of how the evaluative methodologist should approach the project of evaluation. They are focused on other questions too. And I don't deny these questions are philosophically important or interesting. It is interesting to ask what our basic sources of evidence are, what their epistemic standing is, how best to taxonomise mental states, whether there is something interesting to be said about the psychology underlying some of the things we call intuitions, and so on. However, the evaluative methodologist doesn't have to know the answers to these questions, and the idea that the way evaluative methodologists characterise intuitions has to get all these thing right has been a distraction in the methodological literature (and, I suspect, led many to overlook the significance and/or potential import of works in evaluative methodology). I am recommending instead that the way the evaluative methodologist thinks about intuitions sets up their evaluative project with the best potential to give philosophers good advice about how to do philosophy better. ${ }^{27}$

Evaluative methodologists have not always approached the project of evaluating intuitions in the way I recommend. Some have fared well in certain respectscomparatively thin conceptions of intuitions have been de rigueur among those who evaluate intuitions empirically — and a fair amount of effort has been made by some to avoid conducting the debate about the merits of intuitions in monolithic terms, e.g., to limit the claims made by experimental methodologists to certain subject areas (see Weinberg, Nichols \& Stich 2001). However, concerted effort to find factors we can track while philosophising which are relevant to, e.g., the reliability of our intuitions has been comparatively rare, and more research geared towards giving us information which we can use to limit the variability of our intuitions, for instance, would be great.

I have not yet made any positive suggestions about particular distinctions between intuitions the evaluative methodologist could fruitfully make. The main reason for this has been that it will depend upon the terms in which one wishes to evaluate. The distinctions you should pay attention to if you want beautiful methods, will be different from those you should look out for if you want cheap methods. However, suppose, like many in the methodological literature, that we think that

\footnotetext{
27 I imagine that some will still want to object in the following way. Characterise intuitions incorrectly and when you go away and investigate 'intuitions' you won't be conducting a methodological examination of intuitions. That is important. You want to know about the role of proof in philosophy, you better not end up looking at the role of evidence in philosophy. We want to know about the role of intuitions in philosophy, and, that being so, it is really important that methodologists are working with the right account of intuitions. First, let me be clear that I think the way I claim we should think about intuitions in evaluative methodology is the correct way to think about them for that project - even if it doesn't provide an accurate characterisation of some special kind of mental state deserving of the label 'intuition'. However, if someone were really to insist that some other way of thinking about intuitions was correct, then my response would be to distance myself from the project of doing the evaluative methodology of intuitions. If the methodologist who takes my advice doesn't end up doing the evaluative methodology of intuitions, but of something else, then I am not too concerned. So long as they produce information which we can use to make philosophy better, that's what I think is important - that's what I think we all think is important.
} 
our evaluation should be broadly in terms of reliability. What distinctions might it be useful to make?

One important place to look is at what philosophers have said about which sorts of intuitions they deem to be particularly suspect - even if those philosophers make the recommendations for other reasons (with which we might not agree). ${ }^{28}$ Here are some examples: (i) "we shouldn't appeal to intuitions generated in response to thought-experiments whose content radically departs from ordinary experience" (Alexander and Weinberg 2007 - attributed to Austin); (ii) "we shouldn't appeal to intuitions generated in response to thought-experiments that aren't sketched with sufficient detail" (Alexander and Weinberg 2007 - attributed to Austin); (iii) one should avoid intuitions that are influenced by a theory of the target concept (Goldman 2007); and (iv) "an intuition [which is prima facie justified] should be immediate and unreflective, in the sense that it should not be the outcome of considered thought" (Cohen 1986); (v) one should discard "judgements made with hesitation, or in which we have little confidence ... [and] those given when we are upset or frightened ...can be left aside" (Rawls 1972). ${ }^{29}$ Of course, we should also think about the sorts of distinctions which philosophers can track while philosophising. So, some of the suggestions just canvassed don't look like they will be very useful, e.g., it is likely rather difficult to determine when one's intuition is influenced by a theory of the target concept. In any case, in order to use the distinction fruitfully, we would have to have some fairly easy way to work out which of our intuitions were influenced by the target theory at the time of the intuiting. However, some of suggestions look like they could be very useful. To know to that intuitions about thought-experiments whose content radically departs from ordinary experience, e.g., involving time travel, were particularly susceptible to interpersonal and intrapersonal variation could be very helpful. (Of course, whether such intuitions are susceptible in this way is an empirical question. So, evaluative methodologists following such a path will have to do or at least draw upon some empirical enquiry).

\section{Wrapping up}

I have outlined and provided some support for what I take to be a somewhat obvious metamethodology of intuitions, albeit one which has not been at the fore in philosophical methodology. We don't need to have a completely satisfactory account of intuitions in order to do good work in evaluative methodology of intuitions. We don't need to characterise intuitions in a way which would stand up when taxonomising mental kinds or theorising about basic sources of justification.

\footnotetext{
28 A second suggestion might be to look at the empirical literature on intuitions in other domains, e.g., Kahneman and Klein (2009). Of course, there are many reasons to be cautious when doing this. Perhaps psychologists, financiers, weather forecasters, and so on, may not be talking about the same 'intuitions' as us philosophers. Perhaps our practices are relevantly different, e.g., intuitions (if they are used) in weather forecasting are used to predict the future. Perhaps the empirical work has not been sufficiently careful to distinguish distinct mental phenomena, etcetera. Nonetheless, making educated guesses about the distinctions which might be relevant for our purposes, informed by looking at the distinctions found to be relevant to the reliability of things called 'intuitions' in other areas, is an improvement on just guessing.

29 Thanks to an anonymous referee for this last suggestion.
} 
This is good news for the evaluative methodologist. They don't need to get bogged down in tricky debates about what exactly intuitions are, etc. What we want from an evaluation of intuition-use in philosophy is advice on how to do philosophy better; getting bogged down in debates about what exactly intuitions are stops us getting that - stops us getting what we wanted in the first place. I can't emphasise enough the extent to which this is good news for the evaluative methodologist: metamethodogical reflection has revealed a principled defence of a particular conception of intuitions to be used when doing evaluative methodology. Reflecting on the fact that what we want from evaluative methodology is advice on how to do philosophy better, we have arrived at firm conclusions about how to think about intuitions when doing evaluative methodology. We can accept these conclusions even if we don't agree about how intuitions are best characterised when working in other areas of philosophy. We should conceive of intuitions thinly, be prepared to discriminate finely, and to carve to a grain to which, in the process of our philosophising, we are sensitive (or could be with a cheap and easy prosthetic).

Acknowledgements Thanks to Greg Currie, Jules Holroyd, audiences in Nottingham and Vienna and anonymous reviewers for this journal whose comments on this material were very helpful. Acknowledgement is also due to the AHRC for support in the form of a PhD scholarship.

\section{References}

Alexander, J., and J. Weinberg. 2007. Analytic Epistemology and Experimental Philosophy. Philosophy Compass 2 (1).

Andow, J. Forthcoming. Expecting Moral Philosophers to be Reliable. Dialectica.

Andow, J. 2015. How 'Intuition' Exploded. Metaphilosophy (assigned to April 2015 issue).

Bealer, G. 1998. Intuition and the Autonomy of Philosophy. In Rethinking Intuition, eds. M. DePaul and W. Ramsey. Oxford: Rowman and Littlefield.

Bengson, J. 2012. Experimental Attacks on Intuitions and Answers. Philosophy and Phenomenological Research: 86(3).

Bonjour, L. 1998. In Defense of Pure Reason Cambridge University Press.

Brown, J. 2013. Intuitions, Evidence and Hopefulness. Synthese: 190(12) 1-26.

Cappelen, H. 2012. Philosophy without Intuitions. Oxford: OUP.

Cohen, L. J. 1986. The Dialogue of Reason Cambridge University Press.

Cullen, S. 2009. Survey-Driven Romanticism. Review of Philosophy and Psychology 1 (1).

Cummins, R.E. 1998. Reflection on Reflective Equilibrium. In Rethinking Intuition, eds. M. DePaul and W. Ramsey, 113-128: Rowman \& Littlefield.

Goldman, A.I. 2002. Pathways to Knowledge: Private and Public Oxford University Press.

Goldman, A.I. 2007. Philosophical Intuitions: Their Target, Their Source, and Their Epistemic Status. Grazer Philosophische Studien 74: 1-26.

Gopnik, A., and E. Schwitzgebel. 1998. Whose Concepts Are They, Anyway? The Role of Philosophical Intuition in Empirical Psychology. In Rethinking Intuition, eds. M. R. DePaul and W. Ramsey: Lanham: Rowman and Littlefield.

Hales, S.D. 2006. Relativism and the Foundations of Philosophy. Cambridge, MA: MIT Press. Haslanger, S. 2006. What Good Are Our Intuitions? Philosophical Analysis and Social Kinds. Aristotelian Society Supplementary Volume 80 (1): 89-118.

Hintikka, J. 1999. The Emperor's New Intuitions. The Journal of Philosophy 96 (3).

Horvath, J. 2010. How (Not) to React to Experimental Philosophy. Philosophical Psychology 23 (4): 447-480.

Kahneman, D., and G. Klein. 2009. Conditions for Intuitive Expertise: A Failure to Disagree. American Psychologist 64 (6): 515.

Kauppinen, A. 2007. The Rise and Fall of Experimental Philosophy. Philosophical Explorations 10 (2): 95-118.

Kornblith, H. 2007. Naturalism and Intuitions. Grazer Philosophische Studien 74. 
Lewis, D.K. 1983. Philosophical Papers Oxford University Press.

Ludwig, K. 2007. The Epistemology of Thought Experiments: First Person Versus Third Person Approaches. Midwest Studies in Philosophy 31: 128-159.

Lycan, W. 1988. Judgement and Justification. Cambridge: University of Cambridge.

Machery, E., R. Mallon, S. Nichols, and S.P. Stich. 2004. Semantics, Cross-Cultural Style. Cognition 92

Mallon, R., E. Machery, S. Nichols, and S. Stich. 2009. Against Arguments from Reference. Philosophy and Phenomenological Research 79: 332-356.

Maynes, J. 2012. Linguistic Intuition and Calibration. Linguistics and Philosophy 35 (5): 443-460.

Mercier, H., and D. Sperber. 2008. Intuitive and Reflective Inferences. In Two Minds: Dual Processes And Beyond, Jonathan Evans and Keith Frankish, eds., Oxford University Press, April 2009.

Nado, J. 2012. Why Intuition? forthcoming in Philosophy and Phenomenological Research. Nagel, J. Defending the Evidential Value of Epistemic Intuitions: A Reply to Stich. Philosophy and Phenomenological Research.

Nagel, J. 2012. Intuitions and Experiments: A Defense of the Case Method in Epistemology. Philosophy and Phenomenological Research 85 (3): 495-527.

Nahmias, E., S.G. Morris, T. Nadelhoffer, and J. Turner. 2006. Is Incompatibilism Intuitive? Philosophy and Phenomenological Research 73 (1): 28-53.

Nichols, S., S. Stich, and J.M. Weinberg. 2003. Metaskepticism: Meditations in EthnoEpistemology. In The Skeptics, ed. S. Luper, 227-247. Aldershot, England: Ashgate Publishing.

Pust, J. 2012. Intuition. In The Stanford Encyclopedia of Philosophy, ed. E. N. Zalta.

Rawls, J. 1972. A Theory of Justice. Oxford: Clarendon Press.

Shieber, J. 2012. A Partial Defense of Intuition on Naturalist Grounds. Synthese: 187 (2).

Singer, P. 1982. How Do We Decide? The Hastings Center Report 12 (3): 9-11.

Singer, P.2005. Ethics and Intuitions. The Journal of Ethics 9 (3-4): 331-352.

Sosa, E. 1998. Minimal Intuition. In Rethinking Intuition, eds. M. DePaul and W. Ramsey, 257-269: Rowman \& Littlefield.

Sosa, E. 2009. A Defense of the Use of Intuitions in Philosophy. In Stich and His Critics, eds. D. Murphy and M. Bishop, 101-112. Oxford: Wiley-Blackwell.

Sosa, E. 2010. Intuitions and Meaning Divergence. Philosophical Psychology 23 (4): 419-426.

Stich, S., and W. Buckwalter. 2010. Gender and Philosophical Intuitions. Unpublished Manuscript. Available at SSRN: http://dx.doi.org/10.2139/ssrn.1683066

Van Inwagen, P. 1997. Materialism and the Psychological-Continuity Account of Personal Identity. Philosophical Perspectives 11: 305-319.

Weinberg, J. 2007. How to Challenge Intuitions Empirically without Risking Skepticism. Midwest Studies in Philosophy 31 (1): 318-343.

Weinberg, J., and J. Alexander. Forthcoming. The Challenge of Sticking with Intuitions through Thick and Thin. In Intuitions, eds. A. Booth and D. Rowbottom.

Weinberg, J., C. Gonnerman, C. Buckner, and J. Alexander. 2010. Are Philosophers Expert Intuiters? Philosophical Psychology 23 (3): 331-355.

Weinberg, J., S. Nichols, and S. Stich. 2001. Normativity and Epistemic Intuitions. Philosophical Topics 29 ( 1 \& 2).

Weinberg, J.M.; Crowley, S.; Gonnerman, C.; Vandewalker, I.; and Swain, S. (2012). Intuition \& Calibration. Essays in Philosophy: 13(1): 256-283

Williamson, T. 2005. I-Armchair Philosophy, Metaphysical Modality and Counterfactual Thinking. Proceedings of the Aristotelian Society 105 (1).

Williamson, T. 2007. The Philosophy of Philosophy. Oxford: Blackwell.

Williamson, T. 2011. Philosophical Expertise and the Burden of Proof. Metaphilosophy 42 (3): 215-229. 